\title{
Pseudomonas aeruginosa displays an epidemic population structure
}

\author{
Jean-Paul Pirnay, ${ }^{1,2}$ Daniel De Vos, ${ }^{1,3}$ \\ Christel Cochez, ${ }^{1}$ Florence Bilocq, ${ }^{2}$ \\ Alain Vanderkelen, ${ }^{2}$ Martin Zizi, ${ }^{4}$ Bart Ghysels ${ }^{1}$ \\ and Pierre Cornelis ${ }^{1 *}$ \\ ${ }^{1}$ Laboratory of Microbial Interactions, Department of \\ Immunology, Parasitology, and Ultrastructure, Flanders \\ Interuniversity Institute of Biotechnology, Brussels Free \\ University, Paardenstraat 65, B-1640 Sint-Genesius- \\ Rode, Belgium. \\ ${ }^{2}$ Science Department, Belgian Military Medical Service, \\ Queen Astrid Military Hospital, B-1120 Neder-Over- \\ Heembeek, Belgium. \\ ${ }^{3}$ Department of Infectious Diseases, Innogenetics N.V., \\ B-9052 Ghent, Belgium. \\ ${ }^{4}$ Department of Physiology, Faculty of Medicine and \\ Pharmacy, Brussels Free University, B-1090 Brussels, \\ Belgium.
}

\section{Summary}

Bacteria can have population structures ranging from the fully sexual to the highly clonal. Despite numerous studies, the population structure of Pseudomonas aeruginosa is still somewhat contentious. We used a polyphasic approach in order to shed new light on this issue. A data set consisting of three outer membrane (lipo)protein gene sequences (oprl, oprL and oprD), a DNA-based fingerprint (amplified fragment length polymorphism), serotype and pyoverdine type of $73 P$. aeruginosa clinical and environmental isolates, collected across the world, was analysed using biological data analysis software. We observed a clear mosaicism in the results, non-congruence between results of different typing methods and a microscale mosaic structure in the oprD gene. Hence, in this network, we also observed some clonal complexes characterized by an almost identical data set. The most recent clones exhibited serotypes $01,6,11$ and 12. No obvious correlation was observed between these dominant clones and habitat or, with the exception of some recent clones, geographical origin. Our results are consistent with, and even clarify, some

Received 13 February, 2002; revised 29 April, 2002; accepted 29 April, 2002. *For correspondence. E-mail pcornel@vub.ac.be; Tel. (+32) 2359 0221; Fax (+32) 23590399. seemingly contradictory results in earlier epidemiological studies. Therefore, we suggest an epidemic population structure for $\boldsymbol{P}$. aeruginosa, comparable with that of Neisseria meningitidis, a superficially clonal structure with frequent recombinations, in which occasionally highly successful epidemic clones arise.

Introduction

Pseudomonas aeruginosa is noted for its metabolic versatility and its exceptional ability to adapt to and colonize a wide variety of ecological environments (water, soil, rhizosphere, animals) (Goldberg, 2000). It is also known for its capacity to cause disease in cystic fibrosis, burn, cancer and ventilated intensive care patients. Infections caused by $P$. aeruginosa are difficult to treat because of its inherent resistance to antibiotics. There seems to be a consensus about the fact that $P$. aeruginosa clinical isolates are genotypically, chemotaxonomically and functionally indistinguishable from environmental isolates. Römling et al. (1994) reported that the most frequently $(28 \%)$ identified clone in cystic fibrosis patients was also detected at a relatively high frequency $(21 \%)$ in aquatic environments, suggesting a common recent origin of these strains. Rahme et al. (1995) demonstrated the infectivity of a $P$. aeruginosa strain in both plant and animal models. Foght et al. (1996) observed that $P$. aeruginosa strains isolated from a gasoline-contaminated aquifer were indistinguishable, by molecular biological techniques, from clinical isolates. Alonso et al. (1999) reported that both oil-contaminated soil isolates and clinical isolates of $P$. aeruginosa show pathogenic and biodegradative properties. However, the population structure of $P$. aeruginosa is still under discussion. Denamur et al. (1993) and Picard et al. (1994) suggested that the population structure of $P$. aeruginosa was panmictic, but highlighted the need for caution in inferring bacterial population structure from any single class of genetic marker. Comparative sequencing of six genes in 19 environmental and clinical $P$. aeruginosa isolates revealed a high frequency of recombination and a net-like population structure (Kiewitz and Tümmler, 2000). Ruimy et al. (2001) used randomamplified polymorphic DNA (RAPD) typing to study the genetic diversity of $P$. aeruginosa pneumonia, bacteraemia and environmental isolates. They concluded that 
the studied population underwent epidemic clonality with a high rate of genetic recombination and that bacteraemia and pneumonia are not caused by specific clones. Recently, Lomholt et al. (2001) observed an epidemic population structure for a $P$. aeruginosa population isolated mainly from patients with keratitis and their environment. They found evidence for an epidemic clone that is pathogenic to the eye and is characterized by a distinct combination of virulence factors. The above-mentioned studies were, however, somewhat biased, as the studied $P$. aeruginosa populations were often sampled in a relatively small region (mainly one country) and/or focused on a single pathology or specific environment and/or were analysed by only one method. With the call of van Belkum (1996) and Vandamme et al., 1996) for a polyphasic approach in mind, we integrated all phenotypic and genotypic data available to us in a consensus type of clustering to study aspects of the population genetics and epidemiology of $P$. aeruginosa. A data set, consisting of the nucleotide sequences of three outer membrane protein genes (oprl, oprL and oprD), amplified fragment length polymorphism (AFLP) pattern analysis, serotype and pyoverdine type, was combined for $73 P$. aeruginosa isolates, collected from 18 countries, from clinical and environmental habitats. The oprl (249 bp) and oprL (504 bp) genes are coding for the outer membrane lipoproteins I (Cornelis et al., 1989a) and L (Lim et al., 1997) of P. aeruginosa. The oprl gene is conserved among the fluorescent pseudomonads and was found to be useful as a complementary phylogenetic marker for the classification of rRNA group I pseudomonads (De Vos et al., 1998). The oprL gene is conserved in $P$. aeruginosa and has proved to be a useful detection and identification target molecule (De Vos et al., 1997; Pirnay et al., 2000; Jaffe et al., 2001). The $P$. aeruginosa opr $D$ gene (1323 or $1329 \mathrm{bp}$ ) codes for a specialized pore protein, OprD, which allows selective permeation of basic amino acids and their structural analogues such as the carbapenem antibiotic imipenem (Trias and Nikaido, 1990). Analysis of the oprD gene from 55 clinical and environmental isolates revealed important sequence variability and a microscale mosaic structure resulting from multiple recombinational events (Pirnay et al., 2002).

AFLP analysis is a genotyping method based on the selective amplification of a subset of DNA fragments generated by restriction enzyme digestion (Vos et al., 1995). This technique has proved to be highly discriminatory and reproducible, which allows the compilation of standardized patterns in a database (Janssen et al., 1996; Savelkoul et al., 1999).

Pseudomonas aeruginosa strains have been divided into serotypes since 1926 (Aoki, 1926). Since then, many investigators have formed their own serotyping schemata, which has made serological study of $P$. aeruginosa very confusing. Hence, since its publication in 1983 (Liu et al., 1983), most European and American researchers have used the international serogrouping schema for $P$. aeruginosa, comprising 17 groups based on the heat-stable major somatic antigens, for clinical serotyping. The serotyping of $P$. aeruginosa strains, using this standardized schema, allows us to compare the evolutionary relationships between our isolates, provided by the two DNAbased techniques, with earlier published epidemiological data.

To satisfy their need for iron, pseudomonads generally produce high-affinity fluorescent peptidic siderophores, called pyoverdines (PVDs) (Meyer, 2000). In P. aeruginosa, three PVDs (I, II and III), easily differentiated by isoelectric focusing (IEF), have been observed so far, only one being produced by a given strain (Cornelis et al., 1989b; Meyer et al., 1997). The combined results obtained in this study are in agreement with earlier epidemiological studies and clearly indicate that the population structure of $P$. aeruginosa is epidemic.

\section{Results}

\section{Sequence analysis of oprl, oprL and oprD genes}

The oprl, oprL and oprD sequences of the studied $P$. aeruginosa population were aligned and clustered using UPGMA. Alleles were assigned numbers according to their position in the alignment (Fig. 1). The oprl and oprL genes showed sequence variability comparable with that of housekeeping genes, as was to be expected because both genes code for a structural outer membrane lipoprotein. In the dendrograms (UPGMA), based on the similarity of the oprl and oprL genes of the studied $P$. aeruginosa population, supplemented with other members of the rRNA group I pseudomonads (Fig. 2), P. aeruginosa forms a sharply delineated species. Strains LMG 10643 and, to a lesser extent, strains LMG 5031 and Br680 diverge from the rest. With the exception of isolate LMG 10643, all mutations in oprl and oprL were silent, often occurring at the third position of the codon. The oprD gene, on the other hand, showed high sequence variability, a mosaic structure and multiple non-silent mutations, typical of a gene that is under strong selection for diversity (Fig. 1). The oprD gene of strains LMG 10643 and Lw1048 could not be amplified by polymerase chain reaction (PCR).

\section{AFLP analysis}

The AFLP patterns of the $P$. aeruginosa strains and one Pseudomonas pseudoalcaligenes strain were normalized and clustered using UPGMA. By applying the criteria for differentiation of $P$. aeruginosa by AFLP (Speijer et al., 1999), which were based on the criteria for pulsed-field gel 
electrophoresis (Tenover et al., 1995), five clusters of related isolates (with $\geq 80 \%$ homology) were identified (Fig. 3).

\section{Serotype determination}

Sixty-one out of the 73 strains could be serotyped. Six strains were non-agglutinable, and six were polyagglutinable. The predominant serotypes were $01(12.3 \%, 9 / 73)$, $6(10.9 \%, 8 / 73), 11(15.1 \%, 11 / 73)$ and 12 (9.6\%, 7/73) (Table 1).

\section{Pyoverdine typing by IEF}

A majority of the $P$. aeruginosa strains (37/73) produced or were growth stimulated by type II PVD (Table 1). Fifteen isolates produced type I PVD and 14 type III. A few isolates failed to produce enough PVD to allow analysis by IEF. The presence of the receptor for a pyoverdine was therefore determined by a growth stimulation assay. In some cases, growth was stimulated by more than one PVD (Table 1). When this was the case, the pyoverdine that gave the strongest growth stimulation was considered as the cognate one, and the others are indicated between brackets.

\section{Combined analysis}

The data obtained from sequence analysis, AFLP analysis, serotyping and PVD typing of the $73 P$. aeruginosa isolates was combined and analysed using BIONUMERICS biological data analysis software. In the dendrogram from the composite data set (Fig. 4), we identified a limited number of phylogenetic groups with $\geq 80 \%$ similarity. Some subclusters even showed $>90 \%$ similarity. We also observed unique isolates, some of which diverged considerably from the rest of the population. There is also evidence that the relation among the isolates was distorted by recombination. We observed a network of relationships between all analysed parameters (Table 1) and noncongruence between experiments (Fig. 5).

\section{Discussion}

The observation of clones in many bacterial populations has led to the assumption that bacteria reproduce clonally. It was long supposed that point mutations are the major source of genetic variation in bacteria, whereas recombinational exchanges were considered to be rare. This view has changed in recent years. Maynard Smith et al. (1993) used multilocus enzyme electrophoresis (MLEE) to demonstrate that bacterial population structure ranges from the panmictic or fully sexual, with random association between loci (e.g. Neisseria gonorrhoeae), to one that is clonal, with non-random association of alleles, resulting in the frequent recovery of only a few of the possible multilocus genotypes (e.g. Salmonella enterica). Intermediate types of population structure were also reported. Neisseria meningitidis, for example, displays what the authors have called an 'epidemic' structure. Although the population is sexual in the long term, some epidemic clones show significant association between loci. Recently, Feil et al. (2001) used multilocus sequence typing (MLST) (Maiden et al., 1998) to examine the extent and significance of recombination in six bacterial pathogens. In four species (N. meningitidis, Streptococcus pneumoniae, Streptococcus pyogenes and Staphylococcus aureus), they observed a lack of congruence between gene trees, supported by high ratios of recombination to point mutation. In contrast, for Haemophilus influenzae and pathogenic isolates of Escherichia coli, there was some congruence between gene trees, suggesting lower rates of recombination.

In this work, data obtained by four different typing methods, performed on a large batch of unrelated clinical and environmental $P$. aeruginosa isolates, are combined using biological data analysis software in order to get some insights into the population structure of $P$. aeruginosa.

The lack of congruence among experiments (Fig. 5) is most easily explained as the consequence of multiple recombinational events that have eliminated the phylogenetic signal in each tree. This view is supported by the observation of a microscale mosaic structure in the oprD gene (Fig. 1), which supplies direct evidence for recombination. The non-congruence between the AFLP dendrogram and the trees based on sequence analysis could be expected, as sequence diversity is generally caused by single nucleotide polymorphisms, whereas differences in macrorestriction fragment patterns are mainly the result of insertions and/or deletions (Kiewitz and Tümmler, 2000). Although bacterial species in which recombination appears to be common are naturally transformable, there seems to be no obvious correlation between the degree of recombination and the transformability of species. Feil et al. (2001) showed that the naturally transformable $H$. influenzae showed by far greater congruence between gene trees than the non-transformable species $S$. aureus and $S$. pyogenes. They suggested that recombinational exchanges in $S$. aureus and $S$. pyogenes are presumably mediated by phage transduction, the effect of which is as great as that of transformation. $P$. aeruginosa is considered not to be competent for natural transformation. In this context, it is interesting that Ripp et al. (1994) suggested that environmentally endemic bacteriophages are formidable transducers of naturally occurring microbial communities of $P$. aeruginosa.

Hence, the population structure of $P$. aeruginosa is not fully sexual. In the dendrogram based on the comparison of the composite data set (Fig.4), we clearly observed 


\section{oprD}

1111111111112222222223333333333333333334444444444445555555555555555555556666666666666666666777777 45678922456777778890123477890001234455566777890122233555790002223455556677788990000222233457788888001234 al1. 57654067709014570321924369540892702814709259736706958023124782581636785606928170349148903542514578289951 23 AGGACGCGCTAGCCACGCCATACTGCGCCCCCGGCGCTCCCCCGGCCCGAGCGTGCGGCATCCGAGGCCGGTATCATCCACGCCTATTGATGCCACCGCTGCAA

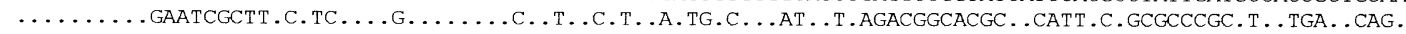

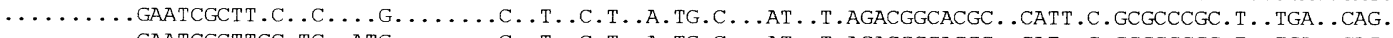

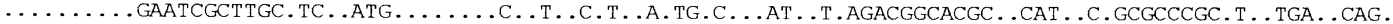

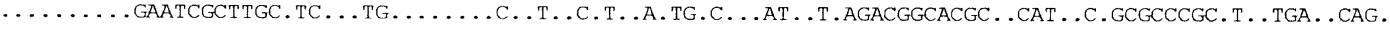

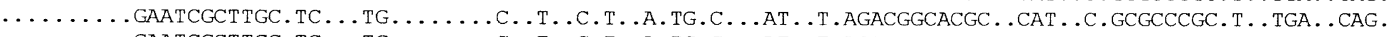

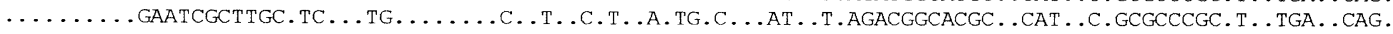

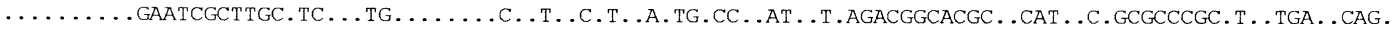

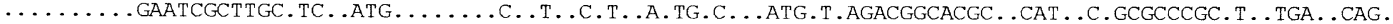

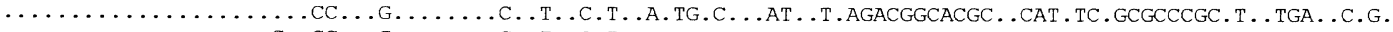

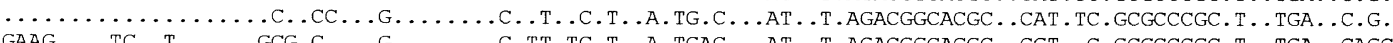

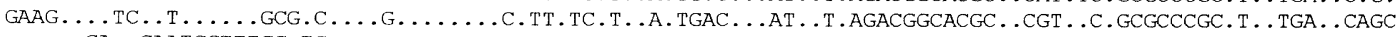

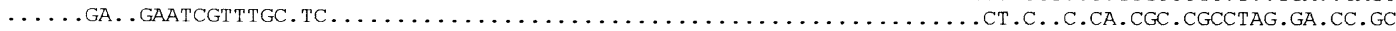

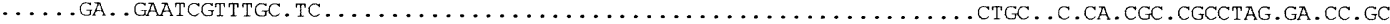

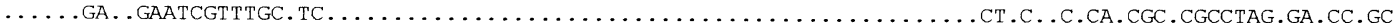

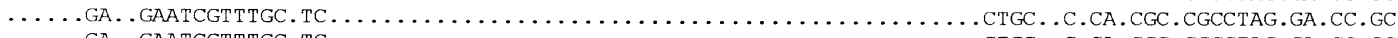
$\ldots \ldots$ GA. GAATCGTTTGC. TC $\ldots \ldots \ldots \ldots \ldots \ldots \ldots \ldots \ldots \ldots \ldots \ldots \ldots \ldots \ldots \ldots \ldots \ldots \ldots \ldots \ldots \ldots \ldots \ldots \ldots \ldots$. C.CA.CGC.CGCCTAG.GA.CC.GC

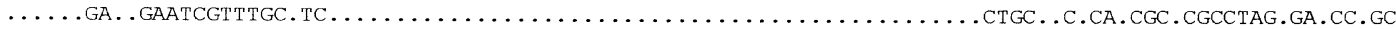

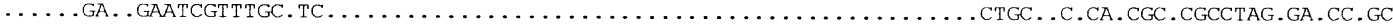

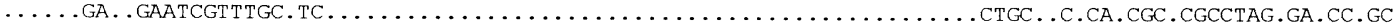

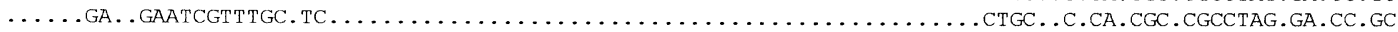

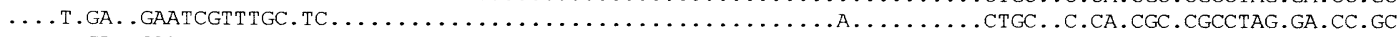

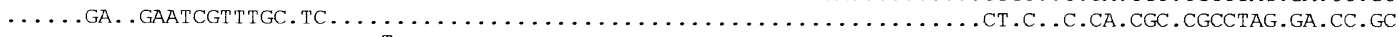

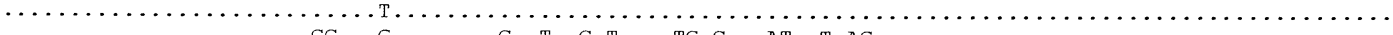

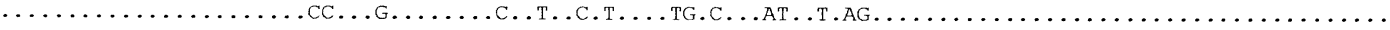

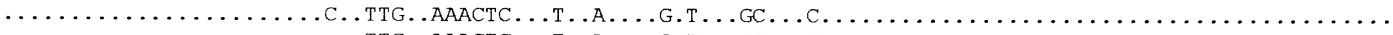

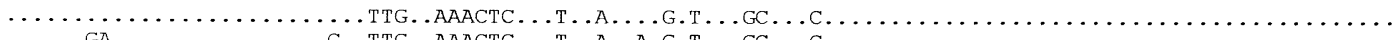

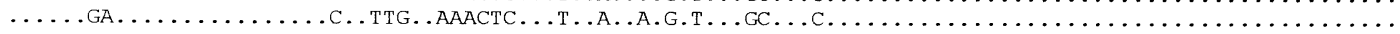

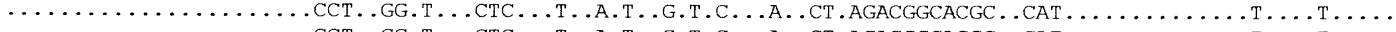

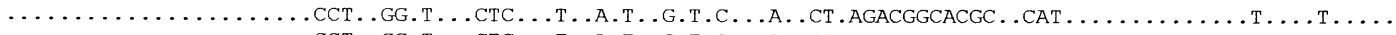

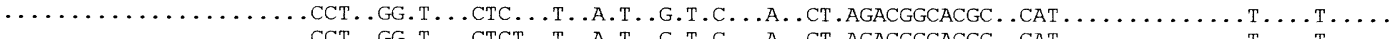

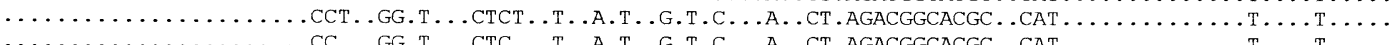

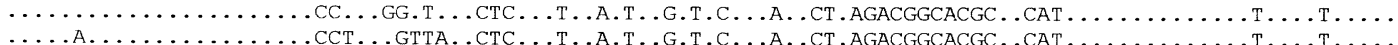

1111111111111111111111111111111111111111111111111111111 7777777778888888888888889999999999999999999000000000000011111111111111111111111111111111112222222222 4556888990224444455667890001122333344456779023456577888900111111222222333333344444444467890013567777 7065359897680236928174610192589046945810589239109857039247456789135679012367801234578916540726730245 CA. TAATGGCATGCACCTTGTTACTCTTTCGCGCTCATCT TCCT TCATCTGCCTTCTCATGTCTAACAAGTCGGATAGAACTAGGCTACGGTTCTCCGGC

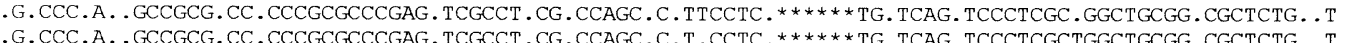

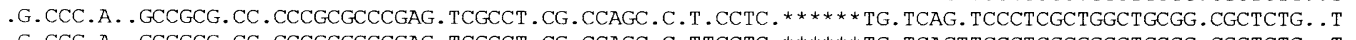

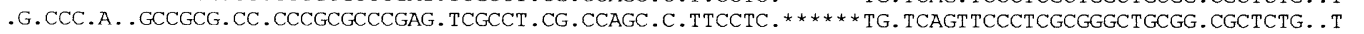

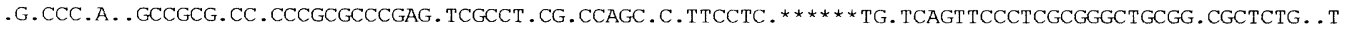

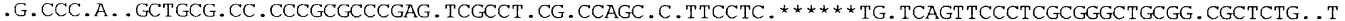

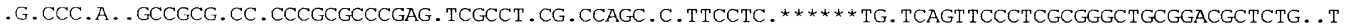
. G.CCC.A. . GCCGCG. CC. CCCGCGCCCGAG. TCGCCT. CG. CCAGC.C.TTCCTC * ***** TG. TCAGT TCCCTCGCGGGCTGCGGACGCTCTG . T

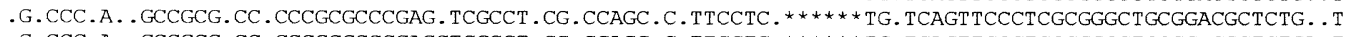

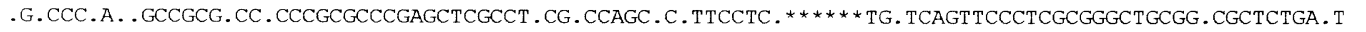

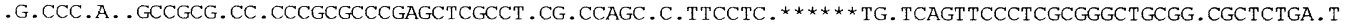
. G. CCC . . . GCCGCG. CC.CCCGCGCCCGAGCTCGCCT . CG . CCAGC . C . TTCCTC . * **** TG. TCAGT TCCCTCGCTGGCTGCGG . CGC . CTGA . T T. . CCCC.TT.C.GCGTCCCCCCGCGCCCG...TC.CC.CC.T.C.GCTCCGTC. TCT $* * * * * *$ TGT TCAG. TCCCTTGCAGGCTG............. T. . CCCC. TT.C.GCGTCCCCCCGCGCCCG... TC.CC.CC. T.C.GCTCCGTC. TCT $* * * * *$ TGTTCAG. TCCCTTGCAGGCTG............

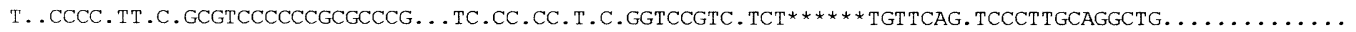

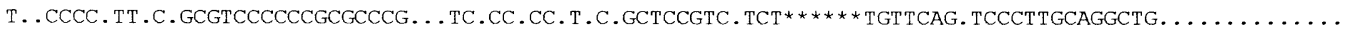

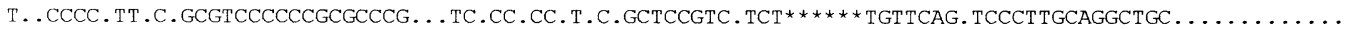

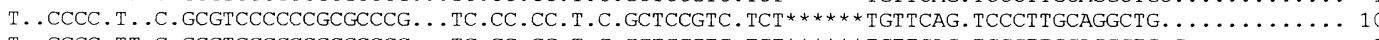

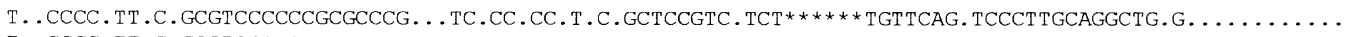
T. . CCCC. TT.C.GCGTCCCCCCGCGCCCG...TC.CC.CC.T.C.GCTCCGTC. TCT $* * * * * *$ TGTTCAG. TCCCTCGCAGGCTG. G........... T. . CCCC. TT.C.GCGTCCCCCCGCGCCCG ...TC.CC.CC.T.C..CTCCGTC. TCT $* * \star * \star$ TGTTCAG. TCCCTTGCAGGCTG. G...........

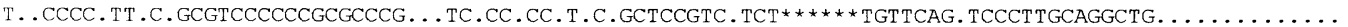

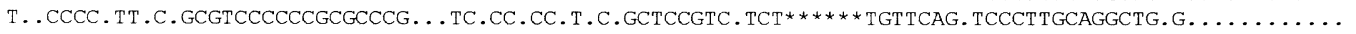

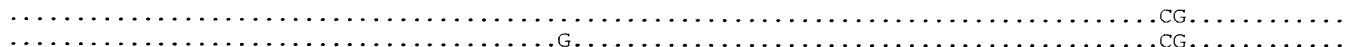

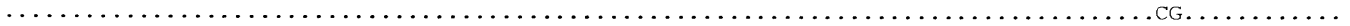

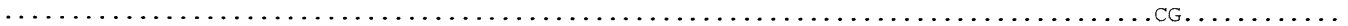

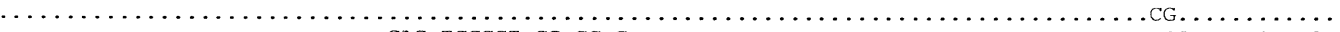

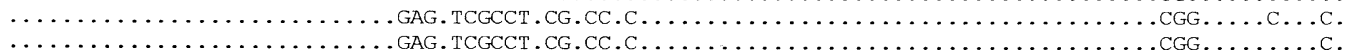

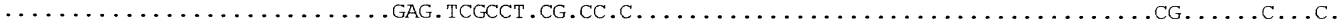

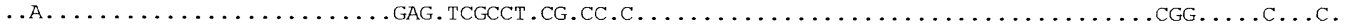

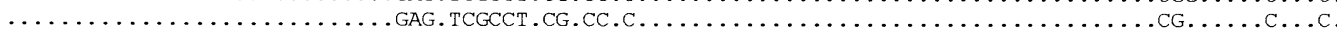

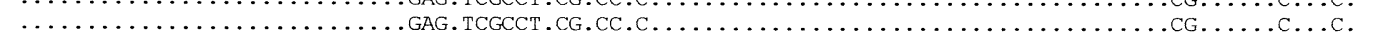

Fig. 1. Polymorphic sites detected in the different alleles of the oprl, oprL and oprD genes of 73 P. aeruginosa isolates. Only the sites that differ from the sequence of the allele of PAO1 (no. 23) are shown. Alleles are arranged according to their positions in the dendrogram of an UPGMA alignment. The number of representatives for each allele is shown on the right. Defective oprD mutations and alleles with unusually high sequence variability are excluded. Gaps are represented by *. 
oprL

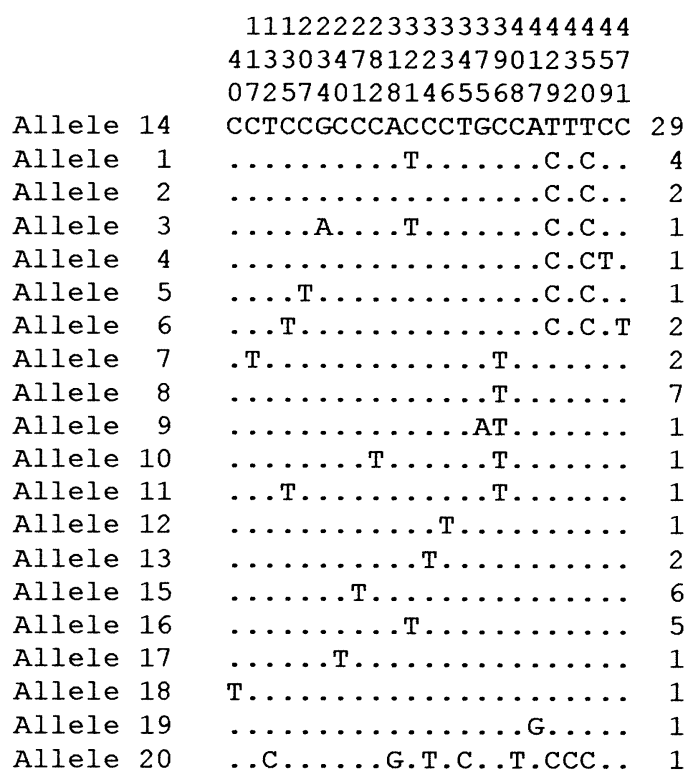

\section{oprI}

$\begin{array}{lrrr} & & 11111 & \\ & & 12789 & \\ & 10435 & \\ \text { Allele 1 } & \text { ATTAC } & 61 \\ \text { Allele 2 } & \ldots . . T & 8 \\ \text { Allele 3 } & \ldots . G . & 1 \\ \text { Allele 4 } & \text { GCC. } & 2\end{array}$

Fig. 1. cont.

seven distinct clonal complexes (CCs) with $\geq 80 \%$ similarity. Most CCs contain strains from geographically and ecologically different sites, suggesting high rates of migration and a remarkable nutritional versatility, acquired through recombination or another evolutionary mechanism. CC A, for example, contains a blood, wound and urine isolate from three distant cities in the USA, a blood isolate from Congo, a sputum, throat and plant rhizosphere isolate from Belgium and a burn wound isolate from Turkey. The variability within each geographic region was nearly as great as within the whole population. In Belgium and The Netherlands, for example, members of CCs A, B, C, E, F and G were isolated.

Clones are transient and, over time, recombination will obliterate the evidence of association. The nearly identical data set of the members of subclusters a, c, d, e and $\mathrm{g}$ (Table 1), resulting in $\geq 90 \%$ homology in the composite data dendrogram (Fig. 4), is evidence of a recent, explosive increase in these clones. These recent clones exhibit serotypes $01,6,11$ and 12 . This observation is in agreement with earlier epidemiological studies. A study of the serotypes of $2952 P$. aeruginosa isolates showed a predominance of serotypes 01, 6 and 11 (Bert and Lambert-Zechovsky, 1996), and serotypes 011 and 12 are frequently associated with multidrug-resistant epidemic strains (Farmer et al., 1982; Grattard et al., 1993; Elaichouni et al., 1994; Richard et al., 1994; Tassios et al., 1998; Dubois et al., 2001). Serotyping of 7089 P. aeruginosa strains, isolated in 16 Belgian hospitals in the period from 1977 to 1986, revealed a steady increase in P. aeruginosa 012 isolates from $2 \%$ in 1982 to $22 \%$ in 1986 (Allemeersch et al., 1988). The majority of these 012 isolates showed the same distinctive pyocin and phage types, suggesting a high degree of homogeneity within the O12 strains in Belgium. A multicentre European study provided evidence for a common $\mathrm{O} 12 \mathrm{P}$. aeruginosa strain in Europe (Pitt et al., 1989). Yet, not all 012 isolates belong to clone c. Serotype 012 clinical isolates Bo546 and Br680 are positioned far away from clone $\mathrm{c}$ in the composite data dendrogram (Fig. 4). Evidence of genotypic heterogeneity among $P$. aeruginosa serotype 012 outbreak isolates has been reported (Bingen et al., 1996).

Although CCs are globally distributed, recent clones are, logically, less widespread (Table 1). Clone $\mathrm{d}$, for example, consists of 10 isolates of a major clone (called clone C) common to patients and aquatic environments in Germany, previously identified by Römling et al. (1994). The occasional clustering of strains of distant geographical origin in recent clones (e.g. strain PAO29 in clone c) illustrates the efficient dispersal of $P$. aeruginosa clones, probably aided by increased mobility of the human population.

The close genetic relation among the isolates of each clone was also detected by AFLP analysis. This shows that AFLP can be used, for example in clinical settings, to recognize epidemic $P$. aeruginosa clones over the short term (10 to maybe hundreds of years).

No significant correlation could be made between the type of PVD produced and the habitat. Recently, De Vos et al. (2001) reported a prevalence of type II PVD isolates in cystic fibrosis patients, but suggested that their might be a correlation between the pyoverdine type and the (clinical) origin of the $P$. aeruginosa isolates. The fact that several $P$. aeruginosa strains are able to use more than one PVD type (Table 1) could be the result of recombinational events involving PVD receptors. Strain LMG 10643 did not produce, nor was able to use, any of the three PVDs. This, together with the aberrant oprl and oprL sequences, makes us doubt that this isolate is a true $P$. aeruginosa. The clustering of isolates with different serotypes is not necessarily the result of recombinational events. Kobayashi et al. (1994) demonstrated that antipseudomonal drugs were able to induce changes in serotype, and possible evidence of a bacteriophage-mediated 
oprL

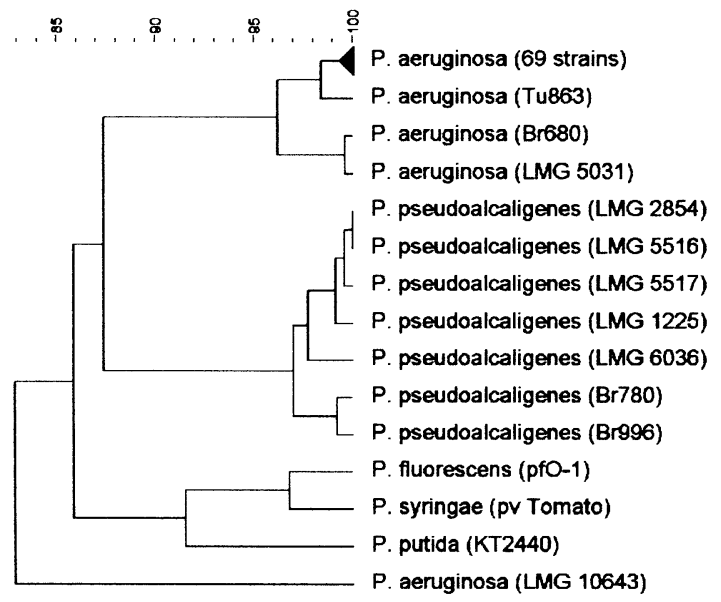

oprl

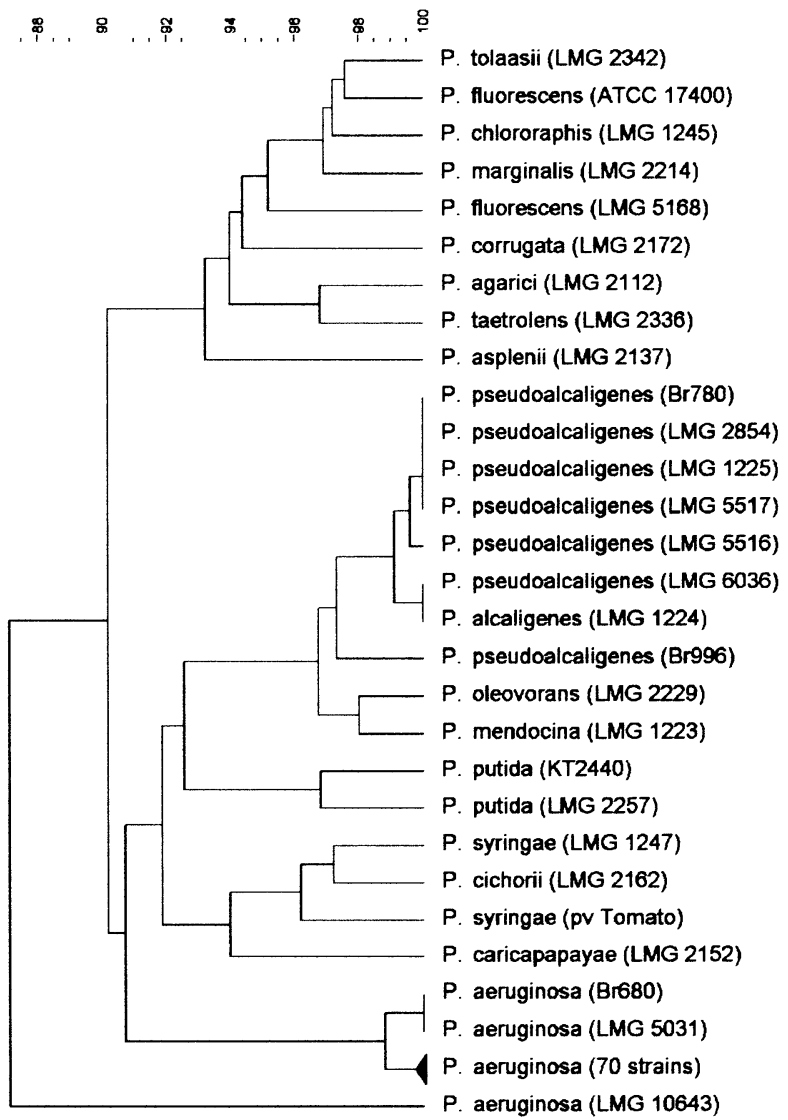

Fig. 2. Sequence similarity trees (UPGMA) based on the comparison of the oprl and oprL nucleotide sequences of the 73 studied $P$. aeruginosa isolates, supplemented with members of the rRNA group I pseudomonads. Sequences of $P$. aeruginosa and $P$. pseudoalcaligenes isolates were determined in this study, P. fluorescens (pf0-1), P. syringae (pv. tomato) and P. putida (KT2440) sequences were retrieved from the unfinished genomic sequence database (http://www.ncbi.nlm.nih.gov/cgi-bin/Entrez/genom_table_cgi) using BLASTN software; all other sequences were retrieved from the NCBI GenBank (http://www.ncbi.nlm.nih.gov/). Percentages of similarity are shown above the dendrogram.

serotype $\mathrm{O} 5$ to $\mathrm{O} 16$ conversion (Newton et al., 2001) was found in the clustering of reference strain PAO1 and strain LMG 14083 in CC B (Fig. 4).

Not that long ago, the ability to identify clusters of isolates with an identical data set from different countries and habitats over a period of time would have been taken as evidence of a clonal structure. The multiple associations of serotypes $\mathrm{O} 11$ and 12 with infection and epidemics and the frequent recovery of only a few of all the possible serotypes $(01,6$ and 11$)$ superficially suggest that the $P$. aeruginosa population is clonal. Our results show an epidemic population structure for $P$. aeruginosa, comparable with that of $N$. meningitidis (Feil et al., 2001), a population composed of a limited number of widespread clones, which originated, through selection, from a background of a large number of relatively rare and unrelated genotypes that are recombining at a high frequency. These adaptive clones are abundant and widespread in nature and are therefore expected to predominate in the patient population.

Future investigations should be directed at factors that play a role in the selective advantages of these highly successful clones in the environment as a whole, instead of restricting analysis to patients and the hospital environment. The cause of the association between virulence and fitness is still unclear (Groisman and Ochman, 1994).

It should be noted that MLST focuses exclusively on housekeeping genes because of selective neutrality. Analysis of these genes provides a more realistic impression of the effect of recombination. In contrast, oprD recombinants can be selectively favoured if, for example, they confer resistance to carbapenem antibiotics. However, we chose to include the oprD sequence data for the following reasons: (i) OprD-related resistance to carbapenems is mainly achieved by non-recombinational events such as point mutations (Pirnay et al., 2002); (ii) it provides direct 


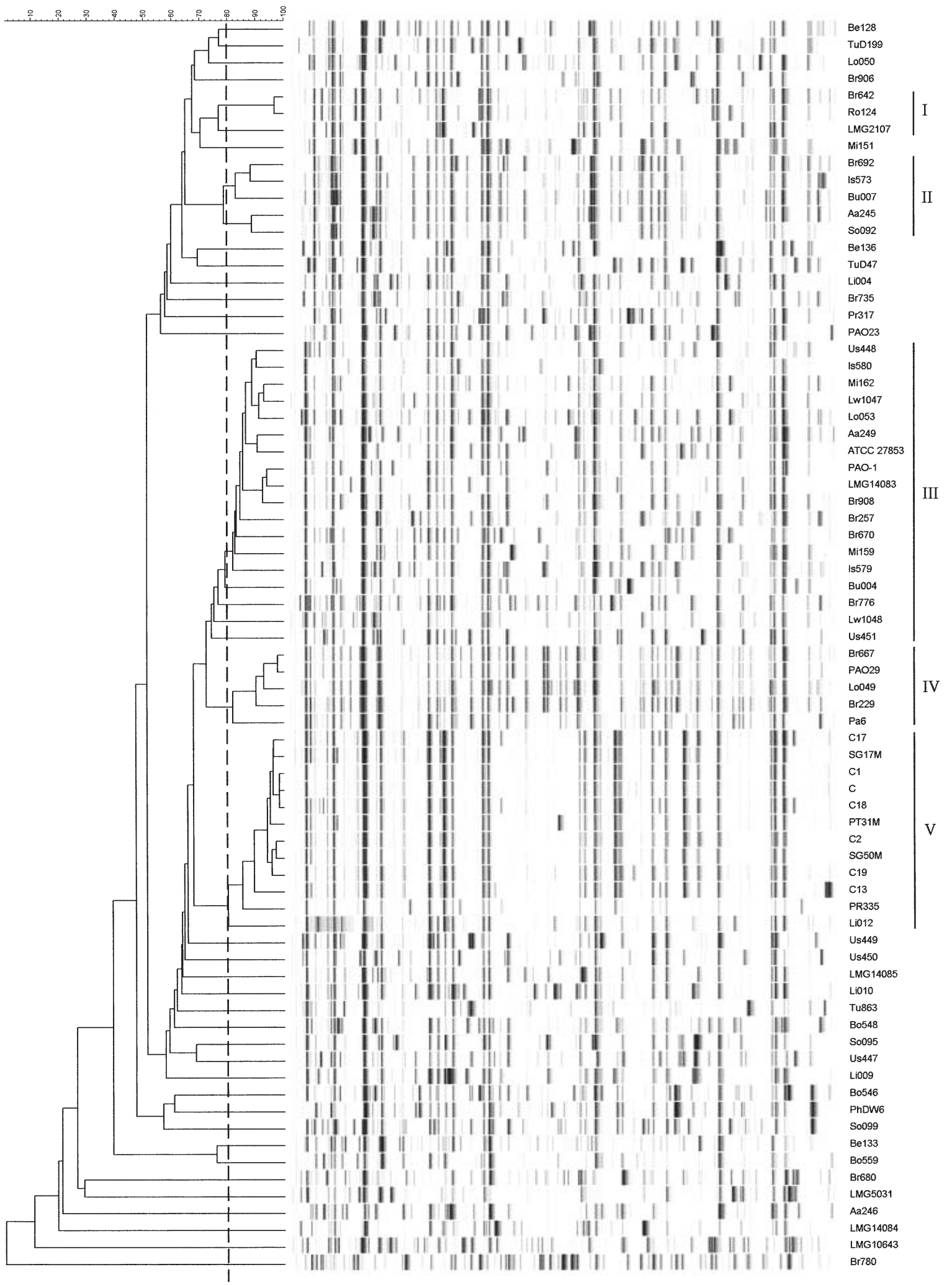

Fig. 3. Normalized AFLP patterns and dendrogram for 73 different $P$. aeruginosa isolates and one P. pseudoalcaligenes isolate (Br780). Cluster analysis was performed with BIONUMERICS software using the Pearson correlation and UPGMA. Percentages of similarity are shown above the dendrogram. Clusters with $\geq 80 \%$ similarity (according to Tenover et al., 1995; Speijer et al., 1999) are indicated by Roman numerals. Clusters I, II and III contain isolates with slightly $<80 \%$ homology. 
evidence for localized recombination in $P$. aeruginosa; and (iii) despite the high sequence variability, members of recent clones show identical oprD sequences, thus illustrating the stability of these clonal complexes. Although we did not perform conventional MLST, we feel that there is sufficient justification for concluding that $P$. aeruginosa displays an epidemic population structure. A more detailed and prospective study involving more clinical and environmental isolates from other parts of the world, as well as housekeeping gene sequence data, is currently under way. We also feel that the exchange of standardized data between laboratories and the creation of international reference databases of typed microorganisms should be encouraged. It will enable the efficient monitoring of changes in microbial populations.

\section{Experimental procedures}

\section{Bacterial strains and growth conditions}

A total of $73 P$. aeruginosa clinical and environmental isolates, collected worldwide, mainly in the late 1980s and 1990 s, with some earlier isolates, were examined. The geographical origin, isolation site and time of all $P$. aeruginosa isolates are listed in Table 1.

The $P$. aeruginosa strains used in this study were kindly provided by: Dr A. T. McManus, US Army Institute of Surgical Research, TX, USA; Dr L. Ménesi, General Hospital St Istvan, Budapest, Hungary; Dr A. Vanderkelen, Queen Astrid Military Hospital, Neder-Over-Heembeek, Belgium; Dr J. A. Clark, Queen Mary's University Hospital, London, UK; Dr A. F. Vloemans, Rode Kruis Ziekenhuis, Beverwijk, The Netherlands; Dr T. Taddonio, University of Michigan, MI, USA; Dr A. Radke, Klinik für Verbrennungs- und Plastische Wiederherstellungschirurgie, Aachen, Germany; Professor R. Konigova, Charles University Hospital, Prague, Czech Republic; Dr R. G. Tompkins, Burns Institute, Shriners Hospital for Children, Boston, MA, USA; Dr B. Tümmler, Medizinische Hochschule, Hannover, Germany; $\mathrm{Dr}$ M. Caneira, Hospital de Santa Maria, Lisbon, Portugal; Professor A. Boudabous, Science Faculty, Tunis, Tunisia; Dr M. Mergeay, Environmental Technology Expertise Centre, Mol, Belgium; Dr A. E. Lim, Jr., St Scholastica's College of Health Sciences, Tacloban City, Philippines; Professor O. Hadjiiski, Scientific Institute of Emergency Medicine Pirogov, Sofia, Bulgaria; Professor K. Taviloglu, University of Istanbul, Istanbul, Turkey; Dr W. D. H. Hendriks, Zuiderziekenhuis, Rotterdam, The Netherlands; Dr G. Wauters, University of Louvain, Brussels, Belgium; Dr O. Vandenberg, Universitair Ziekenhuis St-Pieters, Brussels, Belgium. Strain PAO-1 was kindly provided by Dr C. K. Stover (PathoGenesis Corporation, Seattle, WA, USA). Strain ATCC 27853 was purchased from Gibson Laboratories. P. aeruginosa strains LMG 2107, 5031, 10643 and 14083-5 and P. pseudoalcaligenes strains LMG 1225, 2854, 5516, 5517 and 6036 were purchased from the BCCM/LMG bacteria collection. Unless otherwise indicated, strains were grown on Luria-Bertani broth medium (Gibco BRL Life Technologies) at $37^{\circ} \mathrm{C}$ on a rotary shaker (150 r.p.m.).

\section{PCR and sequencing of the oprl, oprL and oprD genes}

DNA was extracted from overnight $P$. aeruginosa cultures using the High Pure ${ }^{\mathrm{T}}$ PCR template preparation kit (Roche Diagnostics) according to the manufacturer's guidelines.

The oprl, oprL and oprD genes were amplified by PCR, using the primers described in Table 2. PCR was performed in $200 \mu \mathrm{l}$ microcentrifuge tubes. The PCR mixture (50 $\mu \mathrm{l}$ final volume) contained the following: $25.5 \mu \mathrm{l}$ of sterile distilled water, $5 \mu \mathrm{l}$ of $10 \times \mathrm{PCR}$ buffer $\left(500 \mathrm{mmol} \mathrm{I}^{-1} \mathrm{KCl}\right.$ and $100 \mathrm{mmol} \mathrm{I}^{-1}$ Tris-HCl, pH 8.3), $4 \mu \mathrm{l}$ of a deoxynucleotide mixture (dGTP, dTTP, dATP and dCTP; $2 \mathrm{mmol} \mathrm{l}^{-1}$ each), $5 \mu \mathrm{l}$ of $\mathrm{MgCl}_{2}$ (2.5 mmol I-1), $5 \mu$ l of a primer mixture (PS1/2 for oprl, PAL1/2 for oprL or pDF1/R1 for oprD; $10 \mu \mathrm{mol} \mathrm{I}^{-1}$ each), $5 \mu \mathrm{l}$ of template DNA and $0.5 \mu \mathrm{l}$ of AmpliTaq DNA polymerase $\left(5 \cup \mu^{-1}\right)$. All PCR reagents and primers were ordered from PE Applied Biosystems. The amplification was performed in a GeneAmp ${ }^{\circledR}$ PCR system 2400 (PE Applied Biosystems). The amplification programme was set at 50 cycles of denaturation at $94^{\circ} \mathrm{C}$ for $30 \mathrm{~s}$, annealing at $50^{\circ} \mathrm{C}$ or $57^{\circ} \mathrm{C}$, according to the primers (Table 2), for $30 \mathrm{~s}$ and elongation at $72^{\circ} \mathrm{C}$ for $1 \mathrm{~min}$. For the amplification of $P$. pseudoalcaligenes oprL genes, the annealing temperature was lowered to $55^{\circ} \mathrm{C}$. The reaction mixture was put on a $1.5 \%(\mathrm{w} / \mathrm{v})$ agarose gel for electrophoresis and visualization of the PCR product after staining with ethidium bromide on a transilluminator. The DNA bands corresponding to the amplified oprl, oprL and oprD genes were excised from the agarose gel with a clean scalpel. DNA was extracted from the gel slice using the QIAEX II gel extraction kit (Westburg) according to the manufacturer's recommendations. Purified PCR fragment (5 $\mu \mathrm{l})$ was used as a template in the sequencing reaction. PCR primers were used for sequencing. Sequencing of the coding and anticoding strand of the oprDPCR products necessitated two additional internal primers, pDF2 and pDR2 (Table 2). DNA sequencing used an $A B I 377$ automated fluorescence sequencer (PE Applied Biosystems) and the $\mathrm{ABI}$ Prism ${ }^{\circledR}$ BigDye $^{\text {тм }}$ Terminator cycle sequencing ready reaction kit (PE Applied Biosystems) as detailed in the manufacturer's protocols. The oprD gene of isolate Be128 was sequenced directly from genomic DNA. PCR and sequencing were performed in duplicate in order to be able to detect eventual PCR mistakes. Sequences were aligned and clustered using the unweighted pair group method using arithmetic averages (UPGMA) and BIONUMERICS software (Applied Maths).

\section{AFLP}

AFLP used an ABI 377 automated fluorescence sequencer (Applied Biosystems) and the AFLP microbial fingerprinting kit (Applied Biosystems) as detailed in the manufacturer's protocols. The enzymes used were T4 DNA ligase, EcoRI and Tru9l (all purchased from Roche Diagnostics). The primer pair used was EcoRI-O[FAM]/Msel-C. GeneScan500[ROX] internal standard (Applied Biosystems) was coelectrophoresed with each sample in order to allow an accurate calculation of fragment lengths and correction for variation rates and gel distortions. Normalization and fragment sizing were carried out using GENESCAN software (Applied Biosystems). Band patterns were imported into BIONUMERICS software for further normalization (background 


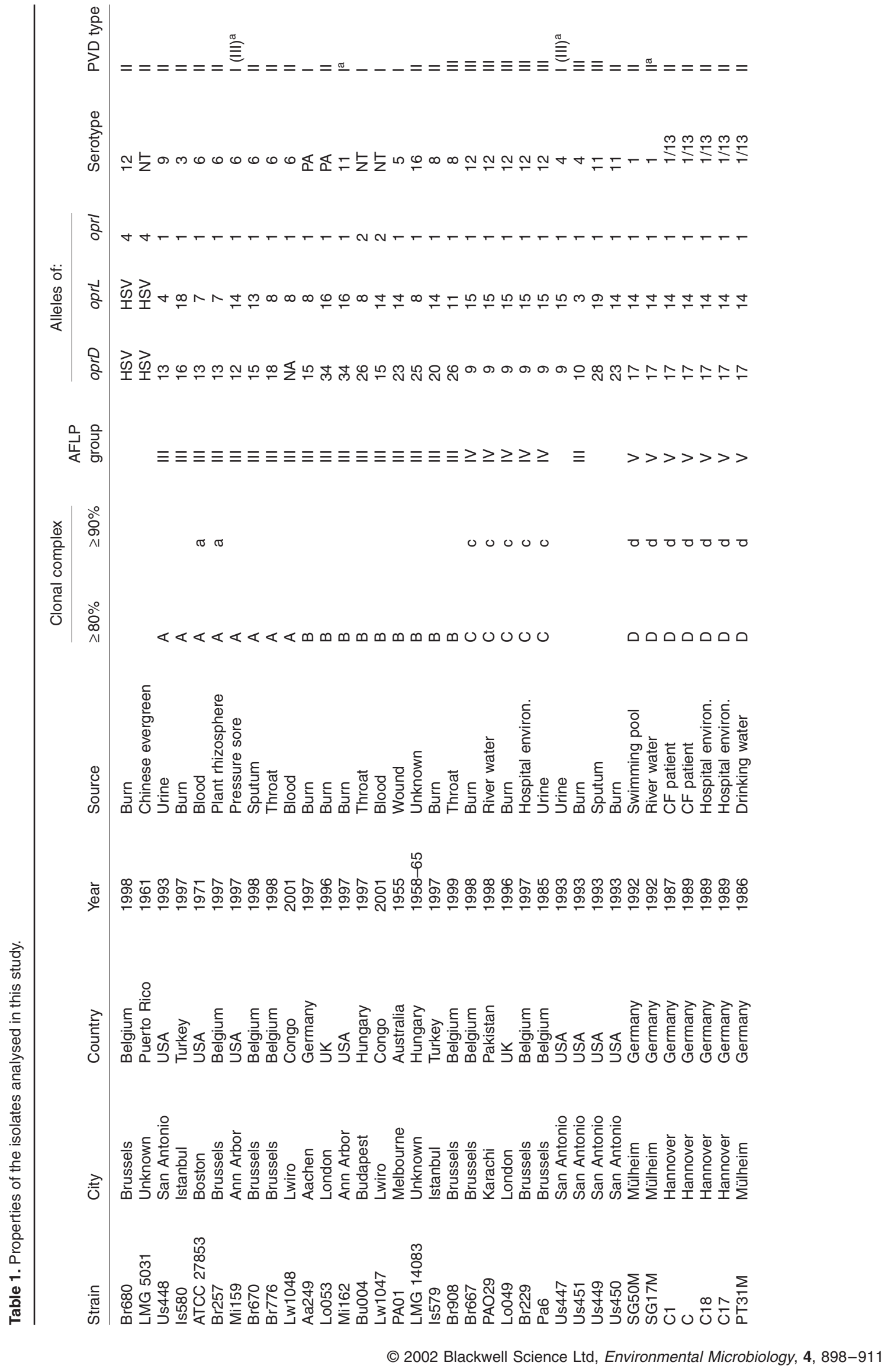




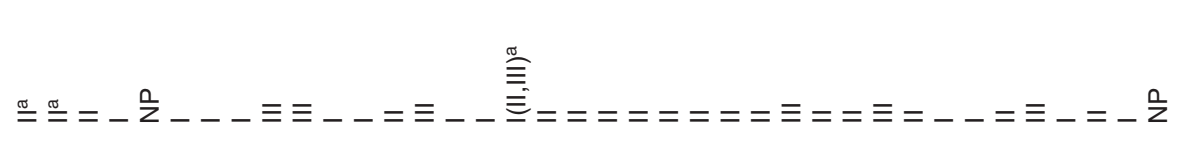

$\stackrel{m}{\longrightarrow} \stackrel{m}{=}$

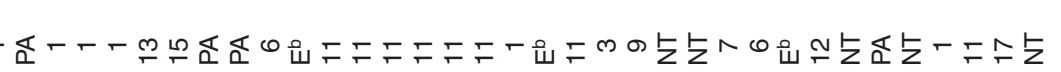

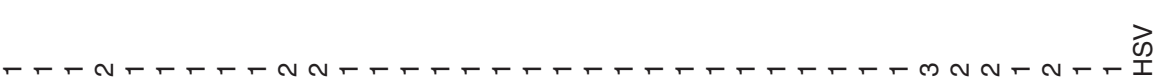

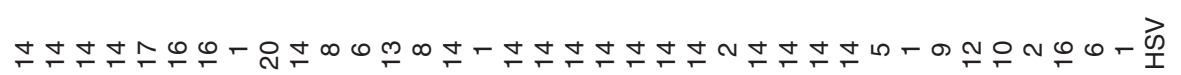

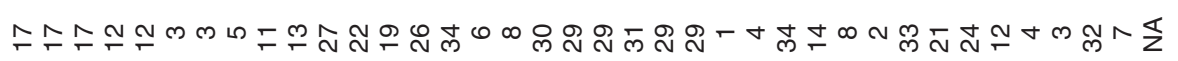

$>>>>---\quad====$

ठ०

คด ดேயய

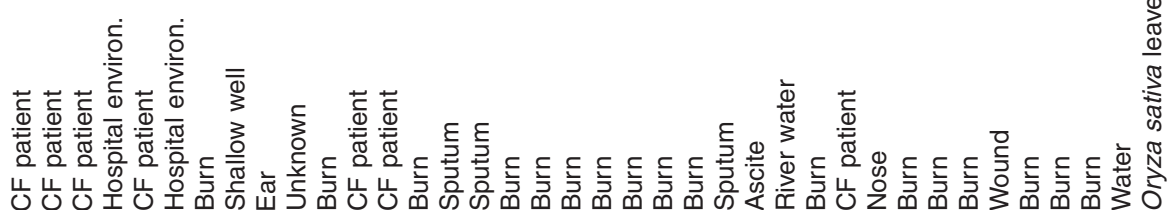

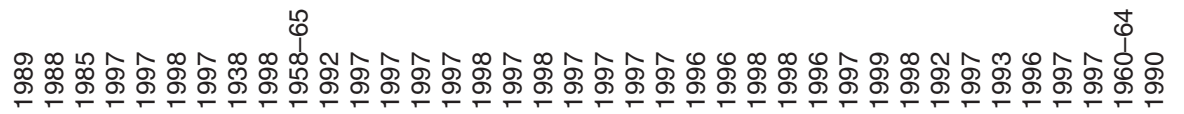

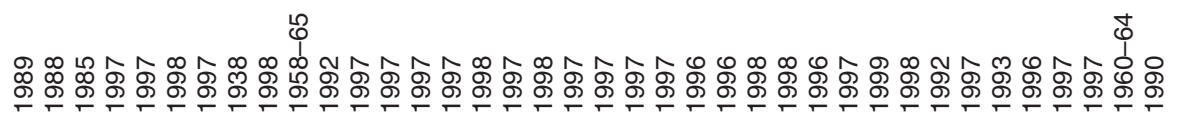

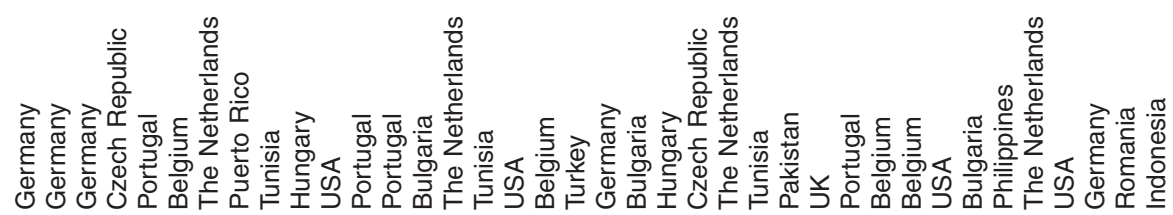

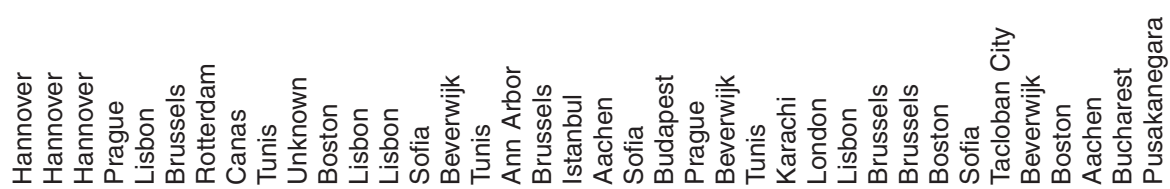

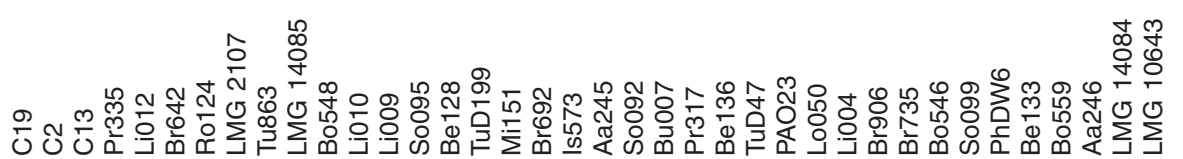




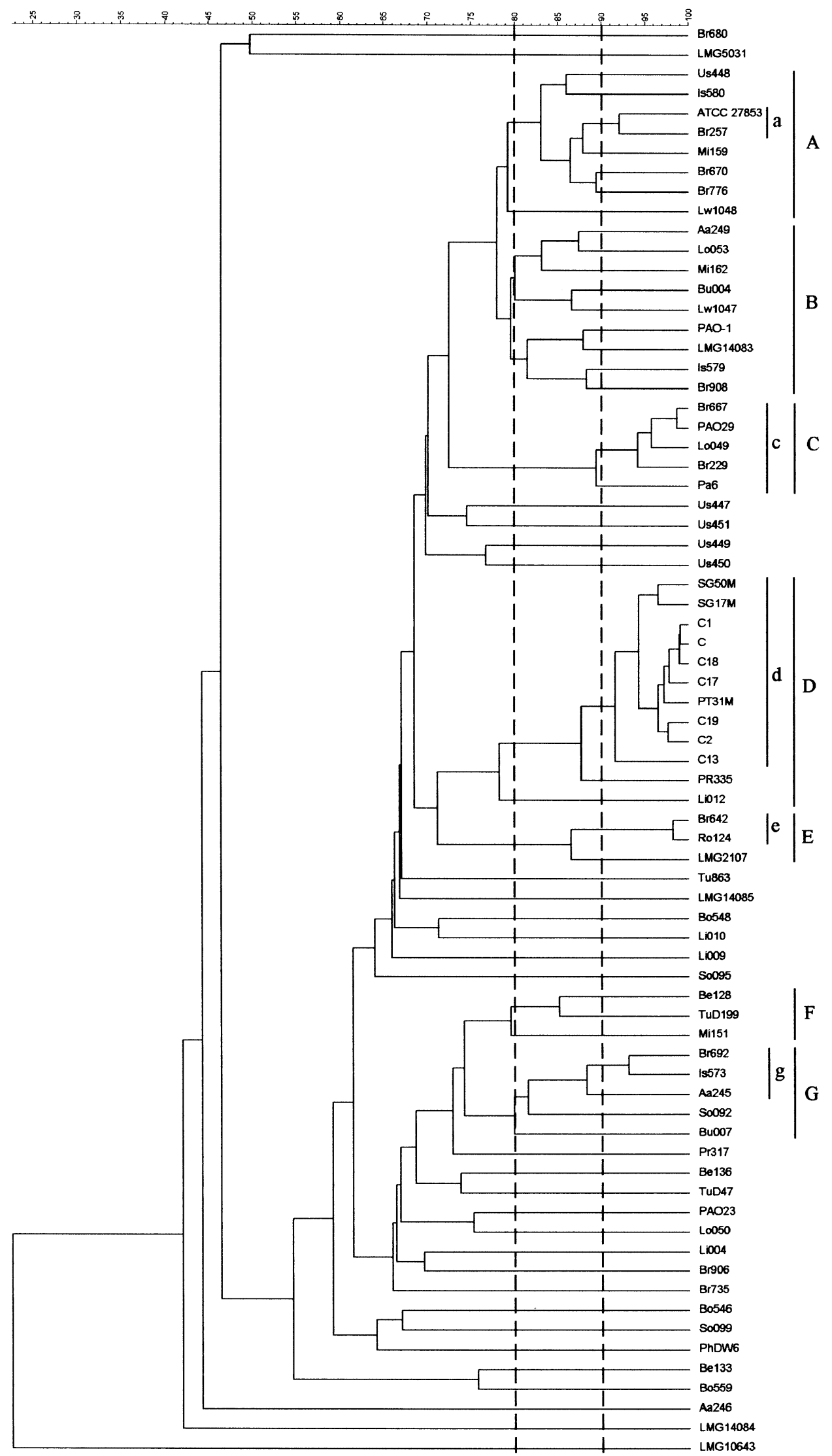




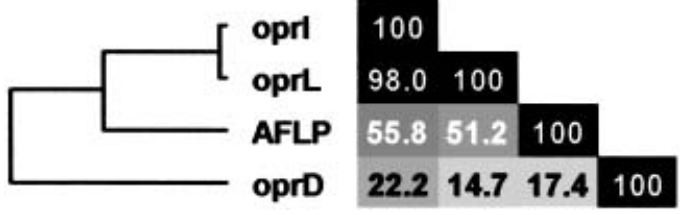

Fig. 5. Matrix of congruence values (percentages) between dendrograms based on the comparison of oprl, oprL and oprD sequences and AFLP patterns, and a dendrogram derived from that matrix. The congruence between experiments was calculated using the Pearson product-moment correlation coefficient.

subtraction, filtering: arithmetic average and band search: minimum profiling $0.5 \%$ relative to maximum value) and cluster analysis (similarity coefficient: Pearson correlation, dendrogram type: UPGMA, optimization: $0 \%$, position tolerance: $1 \%$, uncertain bands were ignored).

\section{Serotyping}

Isolates were serotyped by slide agglutination according to the international serogrouping schema for $P$. aeruginosa (Liu et al., 1983), using a panel of 16 type O monovalent antisera (Sanofi Diagnostics Pasteur).

\section{Pyoverdine typing by IEF}

PVD-IEF was carried out according to the method developed by Koedam et al. (1994), as described previously (Meyer et al., 1997). IEF was performed on Ampholine-PAG plates ( $\mathrm{pH}$ 3.5-9.5; Pharmacia). The following reference strains were included: PAO-1, representative of PVD type I; ATCC 27853, representative of PVD type II; and strain Pa6, a clinical isolate representing PVD type III (Meyer et al., 1997).

\section{Pyoverdine typing by PVD-induced growth stimulation}

The effect on bacterial growth of each of the three known PVDs was tested as described previously (Meyer et al.,
1997). Casamino acid agar (CAA) plates (Cornelis et al., 1992) supplemented with $0.5 \mathrm{mg} \mathrm{ml}^{-1}$ ethylenediaminedihydroxyphenylacetic acid (EDDHA) were homogeneously inoculated with $100 \mu \mathrm{l}$ of a 1:10 diluted overnight bacterial culture at $37^{\circ} \mathrm{C}$ in CAA medium. Sterile filter paper disks $(6 \mathrm{~mm}$ antibiotic disks; Institut Pasteur Productions) were impregnated with $20 \mu$ of each filter-sterilized $1 \mathrm{mM}$ aqueous solution of pyoverdine and placed on the surface of the agar. Plates were incubated at $37^{\circ} \mathrm{C}$ and scored after $24 \mathrm{~h}$ : no stimulation (no growth), slight stimulation (growth, diameter $<10 \mathrm{~mm}$ ) and good stimulation (thick growth, diameter $>15 \mathrm{~mm}$ ). Pyoverdines produced by the type strains PAO1 (PVD type I), ATCC 27853 (PVD type II) and Pa6 (PVD type III) were purified as described previously (Meyer et al., 1997).

\section{Data analysis}

The entire data set, consisting of oprl, oprL and oprD sequences, AFLP pattern, serotype and pyoverdine type of $73 P$. aeruginosa isolates, was analysed and combined using BIONUMERICS (Applied Maths) biological data analysis software. Similarity values were taken from the individual experiments and multiplied by weights (AFLP: 35 , oprD: 11, oprL: 6, serotype: 5, oprl: 2, and PVD type: 1). These weights were an educated guess and designed to compensate for the bias caused by the differences in discriminatory capacity between the experiments in this study. In other words, the weights are proportional to the supposed discriminatory capacity of the different typing methods. A dendrogram from the composite data set was obtained using UPGMA. Congruence between experiments was calculated using the Pearson productmoment correlation coefficient.

\section{Acknowledgements}

We thank all the collectors and providers of the bacterial isolates used in this study. This work was supported by the 'Alphonse and Jean Forton Fund', VZW 'De Vrienden van de Huidbank' and grant JSM-R and T G98/02 from the Belgian Department of Defence. Parts of this paper were presented

Table 2. Primers for PCR and sequencing.

\begin{tabular}{llll}
\hline Primer & Gene & Sequence $\left(5^{\prime}\right.$ to $\left.3^{\prime}\right)$ & Temp. $\left({ }^{\circ} \mathrm{C}\right)$ \\
\hline PS1 & oprl & ATrl & 57 \\
PS2 & $o p r L$ & CTTGCGGCTGGCTTTTTCCAG & 57 \\
PAL1 & ATGGAAATGCTGAAATTCGGC & 57 \\
PAL2 & oprD & CTTCTTCAGCTCGACGCGACG & 57 \\
pDF1 & ATGAAAGTATGAAGTGAGC & 50 \\
pDF2 & oprD & AACCTCAGCGCCTCCCT & 50 \\
pDR1 & CprD & CAGGATCGACAGCGGATAGT & 50 \\
pDR2 & A rD & AGGGAGGCGCTGAGGTT & 50 \\
\hline
\end{tabular}

Fig. 4. Dendrogram (UPGMA) based on the comparison of the composite data set consisting of oprl, oprL and oprD nucleotide sequences, AFLP pattern, serotype and pyoverdine type of $73 P$. aeruginosa isolates. Letters indicate clusters or clonal complexes with $\geq 80 \%$ (caps) and subclusters with $\geq 90 \%$ similarity. Some clusters contain isolates with slightly less homology. Percentages of similarity are shown above the dendrogram. 
at the Pseudomonas 2001 conference, Brussels, Belgium, September 17-21.

\section{References}

Allemeersch, D., Beumer, J., Devleeschouwer, M., De Maeyer, S., Dony, J., Godard, C., et al. (1988) Marked increase of Pseudomonas aeruginosa serotype 012 in Belgium since 1982. Eur J Clin Microbiol Infect Dis 7: 265269.

Alonso, A., Rojo, F., and Martinez, J.L. (1999) Environmental and clinical isolates of Pseudomonas aeruginosa show pathogenic and biodegradative properties irrespective of their origin. Environ Microbiol 1: 421-430.

Aoki, K. (1926) Agglutinatorische einteilung von Pyocyaneusbazillen welche bei verschiedenen menschenerkrangungen nach gewiesen wurden. Zentralbl Bakteriol Parasitenkd Infectionskr Hyg Abt 1 Orig 98: 186-195.

van Belkum, A. (1996) Current trends in typing of bacterial strains for medical purposes. Zentralbl Bakteriol 1045: 249-252.

Bert, F., and Lambert-Zechovsky, N. (1996) Comparative distribution of resistance patterns and serotypes in Pseudomonas aeruginosa isolates from intensive care units and other wards. J Antimicrob Chemother 37: 809813.

Bingen, E., Bonacorsi, S., Rohrlich, P., Duval, M., Lhopital, S., Brahimi, N., et al. (1996) Molecular epidemiology provides evidence of genotypic heterogeneity of multidrugresistant Pseudomonas aeruginosa serotype 0:12 outbreak isolates from a pediatric hospital. J Clin Microbio/ 34: 3226-3229.

Cornelis, P., Bouia, A., Belarbi, A., Guyonvarch, A., Kammerer, B., Hannaert, V., and Hubert, J.C. (1989a) Cloning and analysis of the gene for the major outer membrane lipoprotein from Pseudomonas aeruginosa. Mol Microbiol 3: 421-428.

Cornelis, P., Hohnadel, D., and Meyer, J.M. (1989b) Evidence for different pyoverdine-mediated iron uptake systems among Pseudomonas aeruginosa strains. Infect Immun 57: 3491-3497.

Cornelis, P., Anjaiah, V., Koedam, N., Delfosse, P., Jacques, P., Thonart, P., and Neirinckx, L. (1992) Stability, frequency and multiplicity of transposon insertions in the pyoverdine region in the chromosomes of different fluorescent pseudomonads. J Gen Microbiol 138: 1337-1343.

De Vos, D., Lim, A., Jr, Pirnay, J.P., Struelens, M., Vandenvelde, C., Duinslaeger, L., et al. (1997) Direct detection and identification of Pseudomonas aeruginosa in clinical samples such as skin biopsy specimens and expectorations by multiplex PCR based on two outer membrane lipoprotein genes, oprl and oprL. J Clin Microbiol 35: 12951299.

De Vos, D., Bouton, C., Sarniguet, A., De Vos, P., Vauterin, M., and Cornelis, P. (1998) Sequence diversity of the oprl gene, coding for major outer membrane lipoprotein I, among rRNA group I pseudomonads. J Bacteriol 180: 6551-6556.

De Vos, D., De Chial, M., Cochez, C., Jansen, S., Tümmler, B., Meyer, J.M., and Cornelis, P. (2001) Study of pyover- dine type and production by Pseudomonas aeruginosa isolated from cystic fibrosis patients: prevalence of type II pyoverdine isolates and accumulation pyoverdine-negative mutations. Arch Microbiol 175: 384-388.

Denamur, E., Picard, B., Decoux, G., Denis, J.B., and Elion, J. (1993) The absence of correlation between allozyme and $r$ R R RP analysis indicates a high gene flow rate within human clinical Pseudomonas aeruginosa isolates. FEMS Microbiol Lett 110: 275-280.

Dubois, V., Arpin, C., Melon, M., Melon, B., Andre, C., Frigo, C., and Quentin, C. (2001) Nosocomial outbreak due to a multiresistant strain of Pseudomonas aeruginosa P12: efficacy of cefepime-amikacin therapy and analysis of $\beta$ lactam resistance. J Clin Microbiol 39: 2072-2078.

Elaichouni, A., Verschraegen, G., Claeys, G., Devleeschouwer, M., Godard, C., and Vaneechoutte, M. (1994) Pseudomonas aeruginosa serotype 012 outbreak studied by arbitrary primer PCR. J Clin Microbiol 32: 666671.

Farmer, J.J., III, Weinstein, R.A., Zierdt, C.H., and Brokopp, C.D. (1982) Hospital outbreaks caused by Pseudomonas aeruginosa: importance of serogroup O11. J Clin Microbiol 16: 266-270.

Feil, E.J., Holmes, E.C., Bessen, D.E., Chan, M.-S., Day, N.P.J., Enright, M.C., et al. (2001) Recombination within natural populations of pathogenic bacteria: short-term empirical estimates and long-term phylogenetic consequences. Proc Natl Acad Sci USA 98: 182-187.

Foght, J.M., Westlake, D.W.S., Johnson, W.M., and Ridgway, H.F. (1996) Environmental gasoline-utilizing isolates of Pseudomonas aeruginosa are taxonomically indistinguishable by chemotaxonomic and molecular techniques. Microbiology 142: 2333-2340.

Goldberg, J.B. (2000) Pseudomonas: global bacteria. Trends Microbiol 8: 55-57.

Grattard, F., Gaudin, O.G., Pozzetto, B., Ros, A., and Mbida, A.D. (1993) Genotypic homogeneity of nosocomial Pseudomonas aeruginosa 012 strains demonstrated by analysis of protein profiles, DNA fingerprints and rRNA gene restriction patterns. Eur J Clin Microbiol Infect Dis 12: 57-61.

Groisman, E.A., and Ochman, H. (1994) How to become a pathogen. Trends Microbiol 2: 289-294.

Jaffe, R.I., Lane, J.D., and Bates, C.W. (2001) Real-time identification of Pseudomonas aeruginosa direct from clinical samples using a rapid extraction method and polymerase chain reaction (PCR). J Clin Lab Anal 15: 131-137.

Janssen, P., Coopman, R., Huys, G., Swings, J., Bleeker, M., Vos, P., et al. (1996) Evaluation of the DNA fingerprinting method AFLP as a new tool in bacterial taxonomy. Microbiology 142: 1881-1893.

Kiewitz, C., and Tümmler, B. (2000) Sequence diversity of Pseudomonas aeruginosa: impact on population structure and genome evolution. J Bacteriol 182: 3125-3135.

Kobayashi, L., Hasegawa, M., Miyazaki, S., Nishida, M., and Goto, S. (1994) In vitro and in vivo changes of serotype in Pseudomonas aeruginosa isolates by anti-pseudomonal drugs. J Antibiot (Tokyo) 47: 72-79.

Koedam, N., Wittouck, E., Gaballa, A., Gillis, A., Höfte, M., and Cornelis, P. (1994) Detection and differentiation of 
microbial siderophores by isolelectric focusing and chrome azurol S overlay. Biometals 7: 287-291.

Lim, A., Jr, De Vos, D., Brauns, M., Mossialos, D., Gaballa, A., Qing, D., and Cornelis, P. (1997) Molecular and immunological characterization of OprL, the 18-kDa outer membrane peptidoglycan-associated (PAL) lipoprotein of Pseudomonas aeruginosa. Microbiology 143: 17091716.

Liu, P.V., Matsumoto, H., Kusama, H., and Bergan, T. (1983) Survey of heat-stable, major somatic antigens of Pseudomonas aeruginosa. Int J Syst Bacteriol 33: 256-264.

Lomholt, J.A., Poulsen, K., and Kilian, M. (2001) Epidemic population structure of Pseudomonas aeruginosa: evidence for a clone that is pathogenic to the eye and that has a distinct combination of virulence factors. Infect Immun 69: 6284-6295.

Maiden, M.C.J., Bygraves, J.A., Feil, E., Morelli, G., Russell, J.E., Urwin, R., et al. (1998) Multilocus sequence typing: a portable approach to the identification of clones within populations of pathogenic microorganisms. Proc Natl Acad Sci USA 95: 3140-3145.

Maynard Smith, J., Smith, N.H., O'Rourke, M., and Spratt, B.G. (1993) How clonal are bacteria? Proc Natl Acad Sci USA 90: 4384-4388.

Meyer, J.M. (2000) Pyoverdines: pigments, siderophores and potential taxonomic markers of fluorescent Pseudomonas species. Arch Microbiol 174: 135-142.

Meyer, J.M., Stintzi, A., De Vos, D., Cornelis, P., Tappe, R., Taraz, K., and Budzikiewicz, H. (1997) Use of siderophores to type pseudomonads: the three Pseudomonas aeruginosa pyoverdine systems. Microbiology 143: 35-43.

Newton, G.J., Daniels, C., Burrows, L.L., Kropinsky, A.M., Clarke, A.J., and Lam, J.S. (2001) Three-componentmediated serotype conversion in Pseudomonas aeruginosa by bacteriophage D3. Mol Microbiol 39: 1237-1247.

Picard, B., Denamur, E., Barakat, A., Elion, J., and Goullet, P. (1994) Genetic heterogenicity of Pseudomonas aeruginosa clinical isolates revealed by esterase electrophoretic polymorphism and restriction fragment length polymorphism of the ribosomal RNA gene region. J Med Microbiol 40: 313-322.

Pirnay, J.P., De Vos, D., Duinslaeger, L., Reper, P., Vandenvelde, C., Cornelis, P., and Vanderkelen, A. (2000) Quantitation of Pseudomonas aeruginosa in wound biopsy samples: from bacterial culture to rapid 'real-time' polymerase chain reaction. Crit Care 4: 255-261.

Pirnay, J.P., De Vos, D., Mossialos, D., Vanderkelen, A., Cornelis, P., and Zizi, M. (2002) Analysis of the Pseudomonas aeruginosa oprD gene from clinical and environmental isolates. Environ Microbiol doi: 10.1046/j.14622920.2002.00281.x.

Pitt, T.L., Livermore, D.M., Pitcher, D., Vatopoulos, A.C., and Legakis, N.J. (1989) Multiresistant serotype 012
Pseudomonas aeruginosa: evidence for a common strain in Europe. Epidemiol Infect 103: 565-576.

Rahme, L.G., Stevens, E.J., Wolfort, S.F., Shao, J., Tompkins, R.G., and Ausubel, F.M. (1995) Common virulence factors for bacterial pathogenicity in plants and animals. Science 268: 1899-1902.

Richard, P., Le Floch, R., Chamoux, C., Pannier, M., Espaze, E., and Richet, H. (1994) Pseudomonas aeruginosa outbreak in a burn unit: role of antimicrobials in the emergence of multiply resistant strains. J Infect Dis 170: 377-383.

Ripp, S., Ogunseitan, O.A., and Miller, R.V. (1994) Transduction of a freshwater microbial community by a new Pseudomonas aeruginosa generalized transducing phage, UT1. Mol Ecol 3: 121-126.

Römling, U., Wingender, J., Müller, H., and Tümmler, B. (1994) A major Pseudomonas aeruginosa clone common to patients and aquatic habitats. Appl Environ Microbio/ 60: 1734-1738.

Ruimy, R., Genauzeau, E., Barnabe, C., Beaulieu, A., Tibayrenc, M., and Andremont, A. for the P. aeruginosa Study Group (2001) Genetic diversity of Pseudomonas aeruginosa strains isolated from ventilated patients with nosocomial pneumonia, cancer patients with bacteremia, and environmental water. Infect Immun 69: 584-588.

Savelkoul, P.H.M., Aarts, H.J.M., de Haas, J., Dijkshoorn, L., Duim, B., Otsen, M., et al. (1999) Amplified-fragment length polymorphism analysis: the state of an art. $J$ Clin Microbiol 37: 3083-3091.

Speijer, H., Savelkoul, P.H.M., Bonten, M.J., Stobberingh, E.E., and Tjhie, J.H.T. (1999) Application of different genotyping methods for Pseudomonas aeruginosa in a setting of endemicity in an intensive care unit. J Clin Microbiol 37: 3654-3661.

Tassios, P.T., Gennimata, V., Maniatis, A.N., Fock, C., and Legakis, N.J. (1998) Emergence of multidrug resistance in ubiquitous and dominant Pseudomonas aeruginosa serogroup O:11. J Clin Microbiol 36: 897-901.

Tenover, F.C., Arbeit, R.D., Goering, R.V., Micklesen, P.A., Murray, B.E., Persing, D.H., and Swaminathan, B. (1995) Interpreting chromosomal DNA restriction patterns produced by pulsed-field gel electrophoresis: criteria for bacterial strain typing. J Clin Microbiol 33: 2233-2239.

Trias, J., and Nikaido, H. (1990) Outer membrane protein D2 catalyzes facilitated diffusion of carbapenems and penems through the outer membrane of Pseudomonas aeruginosa. Antimicrob Agents Chemother 34: 52-57.

Vandamme, P., Pot, B., Gillis, M., De Vos, P., Kersters, K., and Swings, J. (1996) Polyphasic taxonomy, a consensus approach to bacterial systematics. Microbiol Rev 60: 407438.

Vos, P., Hogers, R., Bleeker, M., Reijans, M., van de Lee, T., Hornes, M., et al. (1995) AFLP: a new concept for DNA fingerprinting. Nucleic Acids Res 21: 4407-4414. 